\title{
Indium-111 bleomycin complex for radiochemotherapy of head and neck cancer - dosimetric and biokinetic aspects
}

Kalevi J.A. Kairemo 1,3, Hans A. Ramsay², Magnus Tagesson ${ }^{6}$, Antti P. Jekunen ${ }^{3}$, Timo K. Paavonen ${ }^{4}$, Hilkka A. Jääskelä-Saari², Kristian Liewendahl'1, Kaj Ljunggren ${ }^{6}$, Sauli Savolainen ${ }^{5}$, Sven-Erik Strand ${ }^{6}$

1 Department of Clinical Chemistry, University Central Hospital of Helsinki, Finland

2 Department of Otorhinolaryngology, University Central Hospital of Helsinki, Finland

3 Department of Oncology, University Central Hospital of Helsinki, Finland

${ }^{4}$ Department of Pathology, University of Helsinki, Finland

5 Department of Physics, University of Helsinki, Finland

6 Department of Radiation Physics University of Lund, Sweden

Eur J Nucl Med (1996) 23: 631-638

By accident the appropriate reference to Fig. 6, which was added to the manuscript at the revision stage as an example of whole-body distribution of indium-111 bleomycin complex, was not included. The images presented in the figure are from a work in progress, presented in part in [1]. There is a typographical error in the legend: actually the activity source $(3.7 \mathrm{MBq})$ is between the calves.

\section{References}

1. Huhmar H, Korppi-Tommola T, Aronen H, Kallio M, Färkkilä M, Penttilä P, Kairemo K, Savolainen S. In-111 labeled bleomycin uptake by brain tumours. Eur J Nucl Med (1995) 22: 869 (abstr).

Correspondence to: K.J.A. Kairemo 